\title{
Metallography of Al-Si Alloys with Alloying By Fe up to $1 \%$
}

\author{
A.S. Zhilin1, Li Jianguo ${ }^{2}$, V.R. Yalunina ${ }^{1}$, D.S. Varlamenko1, and V.A. Bykov ${ }^{1,3}$ \\ ${ }^{1}$ Ural Federal University named after the first Russian President B.N. Yeltsin, Russia, 620002, \\ Ekaterinburg, street Mira, 19 \\ ${ }^{2}$ Tsinghua University, China, 30 Shuangqing Rd, Haidian Qu, Beijing Shi \\ ${ }^{3}$ Institute of Metallurgy of Ural Branch of the Russian Academy of Sciences, Russia, 620016, \\ Ekaterinburg, street Amundsena, 101
}

\section{Abstract}

Metallographic analysis of aluminum-silicon alloys with different silicon content from 0 to $12 \%$ carried out. All alloys were differed in $2 \%$ by silicon amount from each other and all of them were additionally alloyed with iron in an amount of up to $1 \%$ in order to improve the technological properties in a die casting process. The paper shows the distribution of structural components of alloys made by electronic microscopy.

Corresponding Author:

A.S. Zhilin

a.s.zhilin@urfu.ru

Received: 25 February 2019

Accepted: 9 April 2019

Published: 15 April 2019

Publishing services provided by

Knowledge E

(c) A.S. Zhilin et al. This article is distributed under the terms of the Creative Commons

Attribution License, which permits unrestricted use and redistribution provided that the original author and source are credited.

Selection and Peer-review under the responsibility of The Ural school-seminar of metal scientists-young researchers Conference Committee.
Keywords: aluminum-silicon alloys, metallography analysis, eutectic, structure, cast alloy, alloying, electron microscopy

\section{Introduction}

Industrial interest in aluminum-based alloys is due not only to the desire of designers to reduce the weight of products and equipment, but also to develop heat-conducting materials with high thermal conductivity of alloys [1]. Aluminum has relatively high values of thermal conductivity in the pure state, but any industry is focused on obtaining products from alloys close to eutectic compositions [2-3]. This explains the high manufacturability but unfortunately, with the improvement of manufacturability the thermal conductivity inevitably reduces [4]. Therefore, in this paper we have made an attempt to analyze the structure of alloys with different silicon content melted in laboratory furnaces.

\section{Results and Discussions}

Alloys differ in the content of silicon in an amount of $2 \%$ by weight. In all alloys iron was added because this is a necessary requirement from the part of manufacturability, since iron improves the filling of the mold during injection molding at industry. 
The analysis of thermal conductivity is carried out on equipment for measurements of thermal diffusivity and thermal conductivity by laser flash "NETZSCH LFA 457 MicroFlash". Fig. 1 contains results of measurements of thermal conductivity at room temperature of melted in present work alloys.

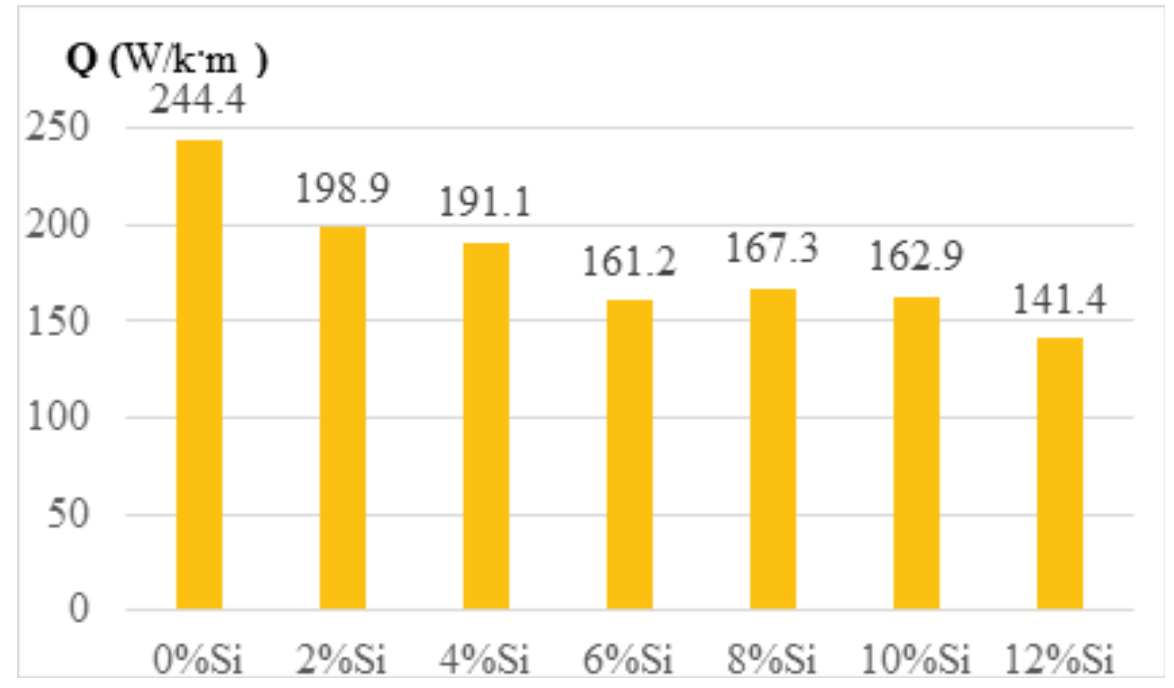

Figure 1: Thermal conductivity at room temperature.

Thermal exchange is a physical property, that is why any alloying reduces the values of thermal conductivity (Fig. 1). Of course, the conditions of obtaining alloys including melting in laboratory furnaces and casting in laboratory allow to obtain structures containing defects of casting origin. One of the main casting defect is porosity. It is not possible to control the porosity in the laboratory using technologies of casting under air pressure, so the influence of the porous structure also leads to a significant decrease in the thermal conductivity of the alloys compared to pure aluminum, the thermal conductivity of which was measured and fixed on $244,4 \mathrm{~W} / \mathrm{k} \cdot \mathrm{m}$ (fig. 1)

Metallographic analysis of alloys using electron microscopy was carried out. Images of the microstructures of the alloys are shown in Fig 2.

The distribution of structural components in alloys is different. Alloys with higher amount of silicon in composition has bigger crystals of pure silicon in the structure. Silicon has low thermal conductivity; big crystals of silicon block heat exchange, which is mainly made by the aluminum metallic matrix. Smaller crystals of silicon in structures with lower amount of silicon allows exchanging of heat up to in 1,5 times better in comparison to the structures with higher amount of silicon. In the alloys with $4 \%$ and $6 \%$ of silicon, it is possible to discuss that pure silicon crystals fixed the grain boundaries. From the point of thermal conductivity it is also not good structural components distribution, because boundaries are also block heat transfer. However, the size of pure silicon crystals is not 

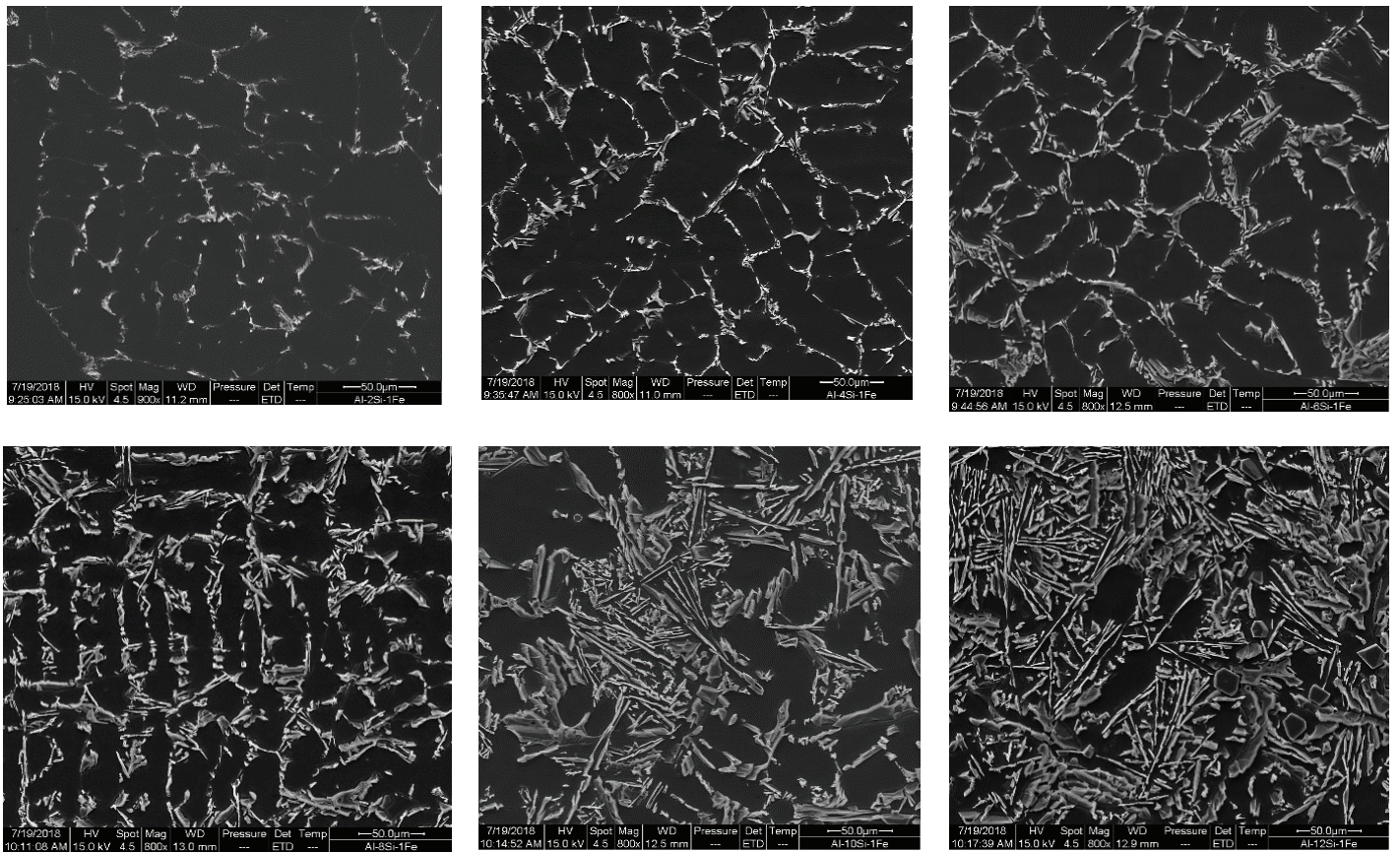

Figure 2: Microstructures of the alloys.

as big as in structures with higher amount of silicon; the impact of blocking the heat transfer by boundaries is also big. It is obvious that alloys with $0 \%$ and $2 \%$ of silicon has the best thermal conductivity due to a small amount of alloying element, however the explanation might be because of the absence of blocking barriers like boundaries or big size particles.

Heat exchange is not only the one property, which is needed to be improved for industrial use of the alloys. The technology of die-casting requires input of iron into the alloy composition for fulfilling the mold. Iron forms phases, which are also block heat exchange properties, however alloy without iron is not possible to use for diecasting technology. Engineers try to make alloys from compositions not far from eutectic composition and not far from pure aluminum. This balance possesses weak relation between physical properties and technological properties. Eutectic compositions allows using cheap technologies for obtaining the products in large amounts at industry. Pure aluminum is not technologically applicable; however, it has the best thermal conductivity in comparison with its alloys.

\section{Conclusion}

It is shown the distribution of structural components in melted alloys with different amount of silicon (from $0 \%$ to $12 \%$ by weight). It is discussed the low thermal conductivity 
reasons. One of this reason is pure silicon distribution in alloys. Big crystals of silicon as well as silicon situated on grains boundaries block thermal exchange of metallic matrix. That is why next going plans of current work is to search the alloying component, which will make all pure silicon crystals smaller.

\section{Acknowledgments}

Authors of work express gratitude to V.V. Tokarev (Ltd. First Foundry) for participation in work.

\section{References}

[1] Haizhi Ye. An Overview of the Development of Al-Si-Alloy Based Material for Engine Applications. JMEPEG (2003) 12:288-297.

[2] M. Jablonski, T. Knych, A. Mamala, B. Smyrak, K. Wojtaszek. Influence of Fe and Si addition on the properties and structure conductivity aluminum. Arch. Metall. Mater. 62 (2017) 3:1541-1547.

[3] A. S. Zhilin, Li Jianguo, V. R. Yalunina, V. V. Tokarev, V. A. Bykov, and V. P. Shveikin, (2018), "Influence of Silicon on Temperature Dependence of Thermal Conductivity of Al-Si-Fe Alloys" in VII All- Russian Scientific and Practical Conference of Students, Graduate Students and Young Scientists on "Heat Engineering and Computer Science in Education, Science and Production”, KnE Engineering, pages 298-301.

[4] A. S. Zhilin, Li Jianguo, V. R. Yalunina, D. S. Varlamenko, V. A. Bykov, and E. V. Derevjankin, (2018), "Influence of Silicon on Thermal Conductivity at Room Temperature of Al-Si-Fe Alloys" in VII All- Russian Scientific and Practical Conference of Students, Graduate Students and Young Scientists on "Heat Engineering and Computer Science in Education, Science and Production", KnE Engineering, pages 294-297. 